\title{
Marked variability in published CMR criteria for left ventricular basal slice selection - impact of methodological discrepancies on LV mass quantification
}

\author{
Jamie Mullally ${ }^{1 *}$, Parag Goyal ${ }^{1}$, Lauren A Simprini ${ }^{2}$, Anika Afroz ${ }^{1}$, Jonathan D Kochav ${ }^{1,3}$, Noel Codella ${ }^{4}$, \\ Richard B Devereux', Jonathan W Weinsaft ${ }^{1,2}$
}

From 16th Annual SCMR Scientific Sessions

San Francisco, CA, USA. 31 January - 3 February 2013

\section{Background}

Left ventricular mass (LVM) quantification by cine-CMR is typically performed by planimetry of contiguous LV short axis images. This approach relies on use of anatomic landmarks or quantitative binary cutoffs to define the basal-most aspect of the LV. Methodological discordance concerning criteria for LV basal slice selection has the potential to alter cine-CMR quantified LVM. This study assessed frequency of methodological variability in published LV basal slice definitions, as well as its impact on cine-CMR quantification of LVM.

\section{Methods}

A Pubmed search was performed using the terms "left ventricular mass", "left ventricular hypertrophy", "myocardial mass", or "hypertrophy" AND "cardiac MRI", "CMR" or "magnetic resonance imaging" [species: human, language: English, publication date: after 1/1/00]. Manuscripts were reviewed by an AHA/ACC level III CMR trained physician for methodology concerning basal slice criteria; methods were categorized based on quantitative and anatomic criteria as defined in each manuscript. Published methods were then applied to an established registry of CAD patients: Cine-CMR images were planimetered for percent circumferential LV myocardium and basal-most LV short axis slices were assigned using the most common quantitative cutoffs determined by literature review.

${ }^{1}$ Medicine/Cardiology, Weill Cornell Medical College, New York, NY, USA Full list of author information is available at the end of the article

\section{Results}

129 original research publications that measured LVM by cine-CMR were identified by systematic literature review. Basal slice criteria were unspecified in $35 \%$, included all LV myocardium in a small minority $(5 \%)$, with the remainder evenly divided in use of anatomic landmarks (30\%) or quantitative cutoffs (30\%) (Figure 1). Marked variability was present in both published anatomic and quantitative criteria for basal slice definition, with the latter most often defined using a binary cutoff of $50 \%$ myocardial circumference during end diastole alone (ED50; 20\%), or during both end-diastole and end-systole (EDS50; 8\%). Among

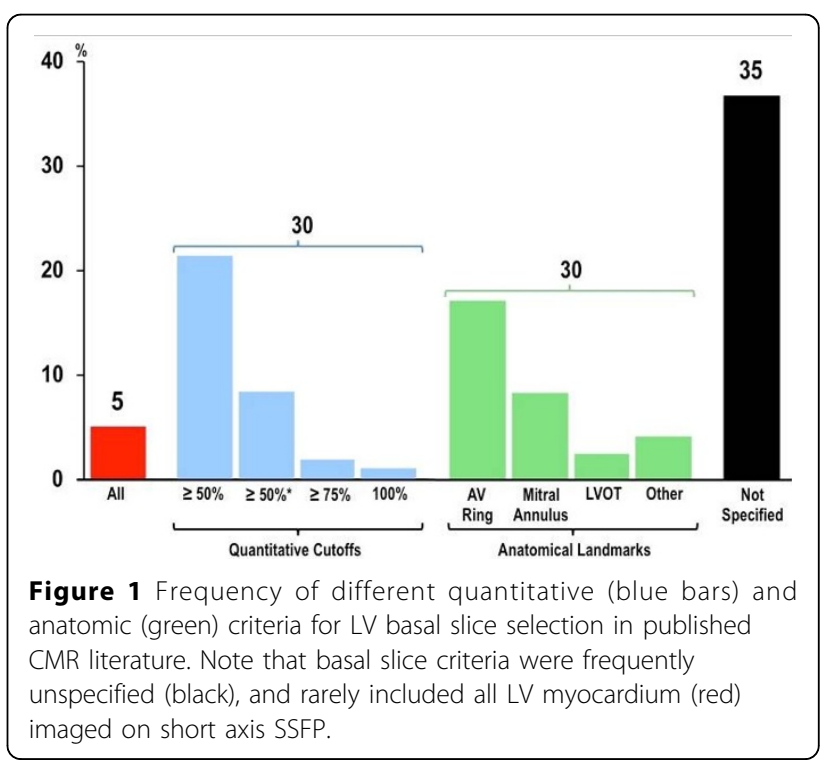


150 CAD patients $(57 \pm 12$ yo, $83 \%$ male, $43 \%$ HTN), circumferential extent of basal slice LV myocardium varied: $31 \%$ of basal slices analyzed contained LV myocardium comprising $<50 \%$ chamber circumference (Figure 2A). LVM contained within basal LV slices strongly correlated with circumferential extent of LV myocardium $(r=0.57$, $\mathrm{p}<0.001$ ) (Figure 2B). LVM excluded using binary cutoffs constituted $5.4 \pm 6.5 \mathrm{gm}\left(2.7 \pm 3.2 \mathrm{gm} / \mathrm{m}^{2}\right)$ for ED50 and 22.0 $\pm 10.0 \mathrm{gm}\left(11.2 \pm 5.0 \mathrm{gm} / \mathrm{m}^{2}\right)$ for EDS50, respectively constituting $3.2 \%$ and $13.0 \%$ of total LVM as calculated when all CMR-evidenced LV myocardium was included.

\section{Conclusions}

Marked variability exists in published CMR literature regarding anatomic and quantitative criteria to define the basal-most LV on short axis cine-CMR. Application of established binary cutoffs frequently excludes LV myocardium from CMR measurements, resulting in 3-13\% decrements in calculated LVM.

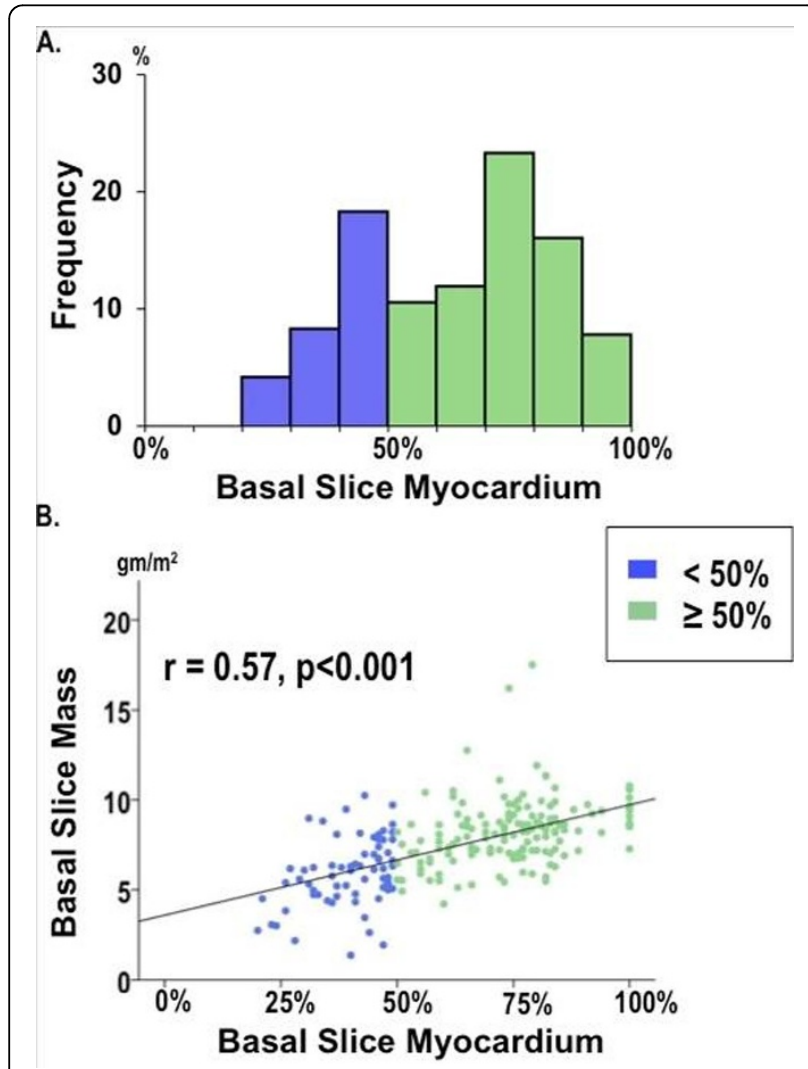

Figure 2 A) Distribution of circumferential extent of LV myocardium among patient cohort (blue $<50 \%$, green $\geq 50 \%$ ). B) Scatter-plot demonstrating correlation between circumferential extent of LV myocardium and LV mass comprised within each basal short axis slice.

\section{Funding}

K23 HL 102249-01, Lantheus Medical Imaging (unrestricted research grant).

\section{Author details}

${ }^{1}$ Medicine/Cardiology, Weill Cornell Medical College, New York, NY, USA. ${ }^{2}$ Medicine/Cardiology, Memorial Sloan Kettering Cancer Center, New York, NY, USA. ${ }^{3}$ Duke University School of Medicine, Durham, NC, USA. ${ }^{4}$ IBM

Thomas J. Watson Research Center, Yorktown, NY, USA.

Published: 30 January 2013

doi:10.1186/1532-429X-15-S1-P101

Cite this article as: Mullally et al:: Marked variability in published CMR criteria for left ventricular basal slice selection - impact of

methodological discrepancies on LV mass quantification. Journal of

Cardiovascular Magnetic Resonance 2013 15(Suppl 1):P101.
Submit your next manuscript to BioMed Central and take full advantage of:

- Convenient online submission

- Thorough peer review

- No space constraints or color figure charges

- Immediate publication on acceptance

- Inclusion in PubMed, CAS, Scopus and Google Scholar

- Research which is freely available for redistribution

Submit your manuscript at www.biomedcentral.com/submit
C Biomed Central 